\title{
Comparison of Obesity/Psychological Disorders Comorbid between Older and Younger Adult Women
}

\author{
Soodeh Razeghi Jahromi ${ }^{1,2}$, Maryam Abolhasani ${ }^{2,3^{*}}$, Maryam Bidadian ${ }^{2}$, Leila Kouti ${ }^{4}$ \\ ${ }^{1}$ Geriatric Group, Sina Hospital, Tehran University of Medical Sciences, Tehran, Iran \\ ${ }^{2}$ Obesity Group, Endocrine and Metabolic Research Center, Sina Hospital, Tehran University of \\ Medical Sciences, Tehran, Iran \\ ${ }^{3}$ Sports Medicine Group, Sina Hospital, Tehran University of Medical Sciences, Tehran, Iran \\ ${ }^{4}$ School of Pharmacy, Ahvaz Jundishapur University of Medical Science, Ahvaz, Iran \\ Email: ${ }^{*}$ Dr_m abolhasani@yahoo.com \\ Received July $28^{\text {th }}, 2013$; revised September $1^{\text {st }}, 2013$; accepted October $3^{\text {rd }}, 2013$
}

\begin{abstract}
Copyright (C) 2013 Soodeh Razeghi Jahromi et al. This is an open access article distributed under the Creative Commons Attribution License, which permits unrestricted use, distribution, and reproduction in any medium, provided the original work is properly cited.
\end{abstract}

\begin{abstract}
Introduction: Epidemiologic data proposed a relationship between obesity and depression in older adults. We conducted this study to evaluate the association between obesity and depressive disorders, as well as a range of eating disorders in old women. Methods: From a total of 1477 clients referred to an outpatient clinic, 212 obese persons ( 97 persons $60+$ and 115 persons 40 - 59 years of age) were enrolled. Data of demographics, comorbidities, anthropometrics, physical activity level, and diet, as well as, depressive and eating disorders were collected. Depressive and eating disorders were assessed using diagnostic structural interview based on DSM-IV-TR (Diagnostic Statistical Manual of Mental Disorder - fourth editionText version). BMI more than or equal to 30 was considered as obesity. Results: The prevalence of dysthymic disorder was significantly lower in older women compared to younger $(p=0.026)$. Comparable but not significant results were observed for major depression disorder, Bulimia Nervosa, and eating disorders not otherwise specified. Conclusion: Our findings suggest that obese older women were less likely to suffer from Comorbid dysthymic disorder/obesity compared to younger.
\end{abstract}

Keywords: Dysthymic Disorder; Obesity; Elderly

\section{Introduction}

In recent decades obesity and depressive disorders including major depression and dysthymic disorder have become notable public health problems (Chan \& Woo, 2010; Sartorius, 2010). A growing body of clinical-based and population-based studies supports the association between obesity and depressive disorders (De Wit et al., 2010; LaCoursiere, 2011; Spitzer et al., 2012). The data from 2005 National Health Interview survey on over 30,000 American adults confirmed the correlation $(\mathrm{r}=0.8)$ between obesity and depression (Blaine, 2008). There are some causal models that explained the obesity and depression comorbidity. One well known model, weight-related stigma, suggests that stigmatizing has prominent role that causes obese patients to also suffer from co-morbid depression. According to this model obesity is a deeply stigmatizing attribute that prompts negative stereotyping and discrimination in others, which, in turn, causes depression and other negative psychological and social outcomes (Puhl, Brownell, Schwartz, \& Rudd, 2005; Puhl, Moss-Racusin, Schwartz, \& Brownell, 2008). The other casual model recognizes that depression can exert causal effects on obesity. A third model combines the two mentioned model. This model suggests negative body image stigmatization of obese individuals could lead to low self esteem and psychological distress generally (Puhl et al., 2005; Puhl et al.,

${ }^{*}$ Corresponding author.
2008). It's supposed that the older obese are less likely to suffer from depressive symptoms, known as "jolly fat" hypothesis (Crisp \& McGuiness, 1976). One of the potential explanations for this hypothesis could be the higher concentration of estrogen in women with higher level of adipose tissue. Estrogen might protect against the development of depression (Kim et al., 2010). Although different studies were dedicated to assessing the relationship between obesity and depression in the elderly, limited data are available on the obesity and dysthymic disorder relation as well as its relationship with eating disorder. Hence in this study we aimed to assess the correlations between obesity, eating and depressive disorders in the elderly compared to middle-aged individuals.

\section{Methods}

\section{Study Design and Sampling}

In this cross-sectional study, participants were randomly selected from a total of 1477 women referred to the outpatient overweight and obesity clinic of Sina University hospital between Jan 2008 and Jan 2012. Individuals were invited to participate in the study by telephone call. The individuals, who accepted to participate, received a comprehensive health screen by sport medicine specialist, nutritionist, and psychologist. Patients with dementia, Alzheimer and other neurodegenerative disease, psychiatric disorders, and malignancies were excluded. 
212 women were enrolled including 97 persons over $60(62.26$ $\pm 5.32)$ and 115 individuals between 40 and 59 years $(49.97 \pm$ 5.52). An informed written consent was obtained.

\section{Measurements}

\section{Basic Data}

Sociodemgraphic and clinical data including educational level, status, age, marital status, smoking habit, and regular exercise were collected. Educational status was classified into $\leq 5$ years, $6-12$ years (college education level), $\geq 13$ years. Smoking was categorized as nonsmoker, regular smoker, and habitual smoker.

Disease history including diabetes, hypertension, cardiovascular disease, hyperlipidemia, thyroid diseases, hepatocellular and gastrointestinal disorders, genitourinary disease, osteoarticular disease, as well as respiratory and lung disease were reported by clients.

\section{Anthropometry}

Body weight was measured to the nearest $0.1 \mathrm{~kg}$ using Seca 755 Dial Column Medical Scale. Height was measured to the nearest $0.1 \mathrm{~cm}$ using a standard stadiometer. Body Mass Index (BMI) was calculated by dividing weight in kilograms by height in square meters. BMI $\geq 30$ was defined as obesity. Waist circumference was measured by the standard tape meter at the maximal narrowing of the waist from anterior view. Hip circumference was measured at the point of maximal gluteal protuberance from the lateral view. Waist to hip ratio was calculated by dividing the waist circumference to hip circumference.

Fat percent and fat free mass (FFM) by Body composition analyzer type BC-418 MA TANITA. The participants were asked not to eat or drink within 4 hours, and not to exercise within 12 hours of the test. They have completely voided the bladder within 30 minutes of the test and have had minimal consumption of diuretic agents.

\section{Physical Activity Level}

The global physical activity questionnaire (GPAQ) was used to assess physical activity level. This questionnaire is valid and reliable for Iranian population. The Global Physical Activity Questionnaire was developed by WHO for physical activity assessment.

It collects information on physical activity level in three settings and sedentary behaviour.

These settings are:

1) Activity at work,

2) Travel to and from places,

3) Recreational activities (Herrmann, Heumann, Der Ananian, \& Ainsworth, 2013).

\section{Depressive and Eating Disorders}

Depressive and eating disorders were assessed using a diagnostic structural interview based on DSM-IV-TR (Diagnostic Statistical Manual of Mental Disorder-fourth edition-Text version) consist of anorexia nervosa, bulimia and non otherwise specified (NOS) (American psychiatric Association, 2000).

\section{Statistical Analysis}

For descriptive analysis of quantitative data, the Mean and
Standard deviation were used. For qualitative data, frequency percentage was reported. To evaluate the association between obesity, depressive and eating disorders OR with 95\% CI was used. Statistical package for the Social Sciences, version 17.0 (SPSS, Chicago, IL, USA) was used to analyze the data.

\section{Results}

Sociodemographic characteristics of the study population and the prevalence of depressive and eating disorders were presented in Table 1. Also the physical activity in both groups was in low active range or sedentary. Table 2 demonstrated the obesity indices and Table 3 presents OR for depressive and eating disorders. As presents in Table 3, obese aged women were less likely to have dysthymic disorder compared to middle-aged obese women 0.27 (95\% CI: 0.083 - 0.9).

Table 1.

Sociodemographic characteristics of the study population and the prevalence of depressive and eating disorders.

\begin{tabular}{|c|c|c|c|}
\hline & & $\begin{array}{c}<60 \text { years } \\
\text { Number } \\
\text { (percent) }\end{array}$ & $\begin{array}{l}\geq 60 \text { years } \\
\text { Number } \\
\text { (percent) }\end{array}$ \\
\hline \multirow{4}{*}{$\begin{array}{l}\text { Marital } \\
\text { status }\end{array}$} & Single & $4(3.6)$ & $1(1)$ \\
\hline & Married & $96(86.5)$ & $74(77.1)$ \\
\hline & Divorced & $8(7.2)$ & $4(4.2)$ \\
\hline & Widowed & $3(2.7)$ & $17(17.7)$ \\
\hline \multirow{3}{*}{$\begin{array}{c}\text { Educational } \\
\text { level }\end{array}$} & $\leq 5$ years & $32(28.6)$ & $59(61.5)$ \\
\hline & $6-12$ years & $61(54.4)$ & $30(31.2)$ \\
\hline & $\geq 12$ years & $19(17)$ & $7(7.3)$ \\
\hline \multirow{9}{*}{$\begin{array}{l}\text { Chronic } \\
\text { conditions }\end{array}$} & Diabetes & $16(15)$ & $22(23.2)$ \\
\hline & Hyperlipidemia & $18(16.8)$ & $39(40.6)$ \\
\hline & Hypertension & $32(29.9)$ & $48(50)$ \\
\hline & Cardiovascular diseases & $13(12.1)$ & $34(35.4)$ \\
\hline & Respiratory diseases & $26(24.3)$ & $22(22.9)$ \\
\hline & $\begin{array}{l}\text { Hepatocellular and } \\
\text { gastrointestinal disorders }\end{array}$ & $57(50.9)$ & $29(30.2)$ \\
\hline & Genitourinary diseases & $17(17.3)$ & $14(14.6)$ \\
\hline & Thyroid diseases & $30(32.7)$ & $19(19.8)$ \\
\hline & Osteoarticular diseases & $65(67)$ & $66(68.8)$ \\
\hline \multirow{3}{*}{ Smoking } & Nonsmoker & $89(77.4)$ & $79(82.3)$ \\
\hline & Regular smoker & $4(3.2)$ & $2(2.1)$ \\
\hline & Recreational smoker & $22(19.4)$ & $15(15.6)$ \\
\hline \multirow{2}{*}{$\begin{array}{l}\text { Depressive } \\
\text { disorders }\end{array}$} & Major depression & $43(37.7)$ & $30(31)$ \\
\hline & Dysthymic disorder & $33(28.3)$ & $9(9.8)$ \\
\hline \multirow[b]{2}{*}{$\begin{array}{l}\text { Eating } \\
\text { disorders }\end{array}$} & Bulimia Nervosa & $4(3.7)$ & $7(7.3)$ \\
\hline & $\begin{array}{c}\text { Disorders not } \\
\text { otherwise specified }\end{array}$ & $23(16.7)$ & $4(4.9)$ \\
\hline
\end{tabular}


Table 2.

Obesity indices in middle-aged women and the elderly.

\begin{tabular}{ccc}
\hline & $\begin{array}{c}<\mathbf{6 0} \text { years } \\
\text { Mean } \pm \text { SD }\end{array}$ & $\begin{array}{c}\mathbf{2 0} \text { years } \\
\text { Mean } \pm \text { SD }\end{array}$ \\
\hline Weight $(\mathbf{k g})$ & $90.7 \pm 17.65$ & $82.9 \pm 12.25$ \\
Height $(\mathbf{c m})$ & $157.8 \pm 5.3$ & $156.6 \pm 9.3$ \\
Body Mass Index (BMI) & $36.65 \pm 7.1$ & $33.77 \pm 5.77$ \\
Waist circumference (cm) & $109.9 \pm 14.05$ & $110.7 \pm 13.37$ \\
Hip circumference (cm) & $121.7 \pm 13.8$ & $118.7 \pm 12.5$ \\
Fat\% & $43.3 \pm 4.5$ & $39.17 \pm 9.6$ \\
Fat free mass $(\mathbf{k g})$ & $51.09 \pm 7.1$ & $49.16 \pm 6.95$ \\
\hline
\end{tabular}

Table 3.

The association between obesity, depressive and eating disorders

\begin{tabular}{cccc}
\hline & OR (95\% CI) & P. value \\
\hline $\begin{array}{c}\text { Depressive } \\
\text { disorders }\end{array}$ & Major depression & $0.83(0.35-1.93)$ & 0.657 \\
$\begin{array}{c}\text { Eating } \\
\text { disorders }\end{array}$ & Bulimia nervosa & $0.56(0.47-0.68)$ & 0.219 \\
& $\begin{array}{c}\text { Disorders not } \\
\text { otherwise specified }\end{array}$ & $0.26(0.052-1.27)$ & 0.075 \\
\hline
\end{tabular}

\section{Discussion}

We found that older obese women were less likely to suffer from dysthymic disorder than their middle-aged compartments.

The inverse association between dysthymic disorder and obesity among elderly Iranian women support the "Jolly Fat" hypothesis (Crisp \& McGuiness, 1976). Our results were fairly in consistent with the previously reported findings in two Asian populations. Elderly Japanese women with chronic medical conditions were less likely to suffer from depressive symptoms (Kuriyama et al., 2006). An inverse relationship was also reported in elderly Chinese women compared to normal weight (Li et al., 2004).

However, in contrast to the studies in elderly Asians, in elderly Caucasians obesity was reported to be positively related to depressive symptoms (Carpenter, Hasin, Allison, \& Faith, 2000). Li et al. hypothesized that this difference might be due to the fact that being a little fat in Asian cultures is not regarded unhealthy, rather showed the wealth of an individual ( $\mathrm{Li}$ et al., 2004). Therefore, obesity might increase self steam in older adults. On the other hand, in western societies the stigma attached to being obese might cause people to suffer lower self esteem and to have more negative self-images, perhaps resulting in higher levels of depression.

This inverse relationship in women might also have biological origin, as in Postmenopausal statues, elderly women with higher levels of adipose tissue have higher levels of estrogen, which might protect against the depressive symptoms (Kim et al., 2010). Our study was limited to women. Also, the crosssectional of the study made us unable to assess whether obesity is a cause or consequence of depressive symptoms. Nevertheless, this study has several advantages. We compare the depres- sive disorders including dysthymic disorder between middleaged and older adults and using random sampling.

In conclusion, we found an inverse relationship between dysthymic disorder and obesity in Iranian elderly women, in consistent with the "Jolly Fat" hypothesis. Public health working against obesity should be cautioned about the potential side effect of depressive symptoms in the elderly women. Prospective studies in middle-aged women are warranted for better understanding of this inverse relationship.

\section{REFERENCES}

Association, A. P. (2000). Diagnostic and statistical manual of mental disorders: DSM-IV-TRÂ®. Arlington, VA: American Psychiatric Publishing.

Li, Z. B., Ho, S. Y., Chan, W. M., Ho, K. S., Li, M. P., Leung, G. M., et al. (2004). Obesity and depressive symptoms in Chinese elderly. International Journal of Geriatric Psychiatry, 19, 68-74. http://dx.doi.org/10.1002/gps.1040

Blaine, B. (2008). Does depression cause obesity? A meta-analysis of longitudinal studies of depression and weight control. Journal of Health Psychology, 13, 1190-1197.

http://dx.doi.org/10.1177/1359105308095977

Carpenter, K. M., Hasin, D. S., Allison, D. B., \& Faith, M. S. (2000). Relationships between obesity and DSM-IV major depressive disorder, suicide ideation, and suicide attempts: Results from a general population study. American Journal of Public Health, 90, 251-257. http://dx.doi.org/10.2105/AJPH.90.2.251

Chan, R. S., \& Woo, J. (2010). Prevention of overweight and obesity: How effective is the current public health approach. International Journal of Environmental Research and Public Health, 7, 765-783. http://dx.doi.org/10.3390/ijerph7030765

Crisp, A. H., \& McGuiness, B. (1976). Jolly fat: Relation between obesity and psychoneurosis in general population. British Medical Journal, 1, 7. http://dx.doi.org/10.1136/bmj.1.6000.7

De Wit, L., Luppino, F., Van Straten, A., Penninx, B., Zitman, F., \& Cuijpers, P. (2010). Depression and obesity: A meta-analysis of community-based studies. Psychiatry Research, 178, 230-235. http://dx.doi.org/10.1016/j.psychres.2009.04.015

Herrmann, S. D., Heumann, K. J., Der Ananian, C. A., \& Ainsworth, B. E. (2013) Validity and reliability of the global physical activity questionnaire (GPAQ). Measurement in Physical Education and Exercise Science, 17, 221-235.

Kim, E., Song, J. H., Hwang, J.-Y., Ahn, K., Kim, J., Koh, Y. H., et al. (2010). Obesity and depressive symptoms in elderly Koreans: Evidence for the "Jolly Fat" hypothesis from the Ansan Geriatric (AGE) Study. Archives of Gerontology and Geriatrics, 51, 231-234. http://dx.doi.org/10.1016/j.archger.2009.10.014

Kuriyama, S., Koizumi, Y., Matsuda-Ohmori, K., Seki, T., Shimazu, T., Hozawa, A., et al. (2006). Obesity and depressive symptoms in elderly Japanese: The Tsurugaya Project. Journal of Psychosomatic Research, 60, 229-235. http://dx.doi.org/10.1016/j.jpsychores.2005.07.010

LaCoursiere, D. (2011). 2. Psychological aspects of obesity in women. In D. Conway (Ed.), Pregnancy in the obese woman: Clinical management (pp. 15-32). Hoboken, NJ: Wiley-Blackwell. http://dx.doi.org/10.1002/9781444391183.ch2

Puhl, R. M., Brownell, K., Schwartz, M., \& Rudd, L. (2005). Coping with weight stigma. In K. D. Brownell (Ed.), Weight bias: Nature, consequences, and remedies (pp. 275-284). New York: Guilford Press.

Puhl, R. M., Moss-Racusin, C. A., Schwartz, M. B., \& Brownell, K. D. (2008). Weight stigmatization and bias reduction: Perspectives of overweight and obese adults. Health Education Research, 23, 347358. http://dx.doi.org/10.1093/her/cym052

Sartorius, N. (2010). Cross-cultural research on depression. Psychopathology, 19, 6-11. http://dx.doi.org/10.1159/000285124

Spitzer, R. L., Levy, D. A., Miller, W. R., Rollnick, S., Sheafor, B. W., Charles, R., et al. (2012). Diagnostic and statistical manual of mental disorders (4th ed.). Washington, DC: American Psychiatric Association. (2000) Text revision (DSM-IV-TR) 